\title{
Does the environmental context of a signalling male influence his attractiveness?
}

\author{
RICHARD N. C. MILNER, MICHAEL D. JENNIONS \& PATRICIA R. Y. BACKWELL \\ School of Botany and Zoology, Australian National University \\ (Received 5 May 2008; initial acceptance 19 June 2008; \\ final acceptance 17 July 2008; published online 5 September 2008; MS. number: D-08-00294)
}

\begin{abstract}
How sexually selected male signals and female sensory systems have evolved so that females can continue to detect and discriminate between potential mates in the face of environmental noise and changes in signaller density has been well studied for acoustic signals. Far less is known about visual signals. We examined the influence of the local signalling environment on male signal attractiveness in the fiddler crab Uca mjoebergi. We used custom-built robotic crabs in two-stimulus mate choice experiments. Females were presented with two identical signals produced in two different signalling environments (simple and complex). The conspicuousness/attractiveness of male claw waving was unaffected by the local environment (physical or social). Male $U$. mjoebergi appear to produce a signal that is highly conspicuous across a wide range of naturally occurring signalling environments and females seem to have a sensory system that is capable of coping with high levels of environmental noise.
\end{abstract}

(C) 2008 The Association for the Study of Animal Behaviour. Published by Elsevier Ltd. All rights reserved.

Keywords: female choice; fiddler crab; signal conspicuousness; Uca mjoebergi; visual noise

Communication systems involve the exchange of a signal between a sender and a receiver to the benefit of both parties (Bradbury \& Vehrencamp 1998). An effective signal is one that the intended receiver can detect against background noise and that allows discrimination of salient characteristics from those of other signals. Numerous environmental factors can affect these processes, including competing signals from other conspecifics, extraneous environmental noise and predation risk, all of which can influence the type of signal emitted (Guilford \& Dawkins 1993).

Mate attraction signals are subject to strong sexual selection imposed by environmental factors that determine the most effective mode of communication as well as finer-scale characteristics of the behaviour and physiology of senders and receivers (e.g. Witte et al. 2005; Doucet et al. 2007). Males with signals that are easier to detect and locate are more likely to mate. To maximize signal efficacy, both sender and receiver evolve traits that increase signal detectability and fidelity. Signals tend to

Correspondence: R. Milner, School of Botany and Zoology, Australian National University, Canberra 0200, A.C.T., Australia (email: richard.milner@anu.edu.au). match well the environment in which they are produced, while receivers evolve sensory systems that compensate for environmentally induced signal degradation during transmission (Endler 1992). For example, while most frogs use acoustic signals to attract mates, noise from cascading water has led to the partial loss of such signals in the Panamanian golden frog, Atelopus zeteki. Instead, visual signals comprising limb movements are used as they are more efficacious in an acoustically noisy environment (Lindquist \& Hetherington 1996).

For a visual signal, detectability or conspicuousness is largely determined by the extent to which it is a nonrandom sample of the surrounding environment (Uy \& Endler 2004). This is achieved by (1) colour, (2) brightness, (3) pattern geometry and (4) movement contrast (Bradbury \& Vehrencamp 1998). Signals evolve to increase the signal to noise ratio (Ryan 2007), with receivers often responding preferentially to those that are bigger, brighter, faster and offer more visual contrast (Andersson 1994). Fine-scale aspects of signalling behaviour, such as microhabitat choice by signallers, can further boost the signal to noise ratio and reduce potential signal degradation (Endler 1992; Chunco et al. 2007). For example, in golden-collared manakins, Manacus vitellinus, males behaviourally enhance their conspicuousness by altering 
their signalling environment: they clear a circular court and then display to females who assess males from elevated perches (Endler \& Thery 1996). A cleared court provides a simple visual background that improves display conspicuousness (Uy \& Endler 2004). Similarly, there is evidence from guppies, Poecilia reticulata (Endler 1991), wiretailed manakins, Pipra filicauda (Heindl \& Winkler 2003a) and the moth Hepialus humuli (Andersson et al. 1998) that males exploit specific light environments that increase within-body contrast of colour patches used in sexual displays and elevate contrast with the background (Heindl \& Winkler 2003b).

There is relatively good information on how the physical environment (e.g. understorey density, canopy cover) and environmental noise affect the detectability of acoustic signals. The masking effect of background noise on call detectability has been shown for many species (Morton 1975; Wollerman 1999; Wollerman \& Wiley 2002; Slabbekoorn \& Peet 2003; Witte et al. 2005; Patricelli \& Blickley 2006; Warren et al. 2006; Swaddle \& Page 2007). It selects for shifts in signal properties. For example, urban great tits, Parus major, that live in noisy industrial locations differ from those in quiet residential areas by using higher minimum frequencies in their song, presumably to reduce the masking effect of low-frequency noise from cars and planes (Slabbekoorn \& Peet 2003). In contrast, we know far less about environmental effects on visual signals in the field (Stuart-Fox et al. 2007). It is only because of recent advances in robotics, video playback and spectrometry that field studies of visual communication systems have become possible (Ryan 2007). For example, Ord et al. (2007) provided one of the first studies illustrating the influence of movementbased visual noise on visual displays, showing that signal speed in two Puerto Rican lizards (Anolis cristatellus and $A$. gundlachi) had to be increased to improve communication in environments of rapidly moving vegetation.

The presence of other signallers can also have a pronounced effect on a receiver's ability to detect and discriminate relevant signals (Wollerman \& Wiley 2002). Psychophysical studies of humans show that an excess of signals can generate an erroneous response or lack of response because of 'cognitive overload' (Hutchinson 2005). Similarly, for acoustic signals used by animals, changes in the density and distribution of calling males can impair a female's ability to discriminate between potential mates (Wollerman 1999; Wiley 2006). Again, however, there is less evidence for this type of 'confusion effect' for visual signals, largely because of the practical difficulties of generating artificial signals in the field.

We used robots to test how the conspicuousness, and thus attractiveness, of visual courtship signals produced by male fiddler crabs (Uca mjoebergi) is influenced by the signalling environment. Male fiddler crabs wave their greatly enlarged claw to attract females as mates. In most species, including $U$. mjoebergi, there is great variation in the environment in which males wave and females select mates (Crane 1975). For example, some males display in full sunlight on exposed mudflat, while others are shaded by mangrove trees; some wave among mangrove roots and a moving background of waving leaves, while others are in the flat, treeless habitat of the open mudflat (Nobbs 2003). There is also substantial variation in the social environment because of changes in the local density of waving males (Christy 1980). Our aims in this study were to investigate the influence of (1) light level, (2) background complexity, (3) foreground complexity, (4) a combination of these factors, and (5) social complexity on male signal conspicuousness/attractiveness.

\section{METHODS}

Uca mjoebergi is a small fiddler crab (carapace width 5$20 \mathrm{~mm}$ ) that inhabits intertidal mudflats in northern Australia (Crane 1975). They occur in dense, mixed-sex colonies (Reaney \& Backwell 2007a). Both sexes defend territories that are centred on a burrow. Males have one greatly enlarged claw (an order of magnitude longer than the feeding claw), which they wave at females during courtship (Reading \& Backwell 2007). During the mating period, receptive females leave their territories and visit the burrows of a series of courting males before eventually selecting a mate (Reaney \& Backwell 2007b). Females are usually simultaneously faced with several potential mates. Observations in the wild show that females more often approach males with higher wave rates and bigger claws (L. T. Reaney, unpublished data). Playback experiments using robotic crabs confirm that females have preferences for specific male traits (e.g. claw size, wave rate and wave leadership, i.e. waves beginning before those of its neighbours; Reaney et al. 2008; E. Curran, M. D. Jennions \& P. R. Y. Backwell, unpublished data). Our study was undertaken at East Point Reserve, Darwin, Australia. Mate choice trials were run for 5-6 days during peak mating periods each neap tide from September to December 2007.

We surveyed the habitat of $U$. mjoebergi along seven $20 \mathrm{~m}$ transect lines, placed $8 \mathrm{~m}$ apart and set perpendicular to the shoreline. At $50 \mathrm{~cm}$ intervals along each transect, the closest male crab $(<30 \mathrm{~cm})$ was selected and his immediate habitat $(<10 \mathrm{~cm})$ was scored for shade (absent, mottled or heavy), the presence of mangrove roots $(\geq 3$ roots $=$ present), and presence of shells or leaves (for both, $\geq 1=$ present).

The field site used for the mate choice trials was an environmentally homogeneous clearing within the natural distribution of $U$. mjoebergi. All conspecific and heterospecific crabs within $2 \mathrm{~m}$ of the choice arena were removed and released elsewhere on the mudflat. For the experiments we used custom-built robotic crabs (see Reaney et al. 2008 for construction details). In brief, each robotic crab has a claw movement engineered to resemble closely that of a courting male U. mjoebergi. For all experiments we set the wave rate at 8.4 waves/min and the artificial claw size was $17.5 \mathrm{~mm}$ (population mean $\pm \mathrm{SE}=17.79 \pm 0.124 \mathrm{~mm}, N=704$, Morrell et al. 2005), and both claws waved in synchrony to avoid a leadership effect (Reaney et al. 2008). The two robotic crabs were placed $5 \mathrm{~cm}$ apart and $20 \mathrm{~cm}$ from the female release point. These distances fall within the natural ranges of intermale distances during a bout of waving $(5 \mathrm{~cm})$ and the distances between a female and a set of displaying males when she makes her mate choice $(20 \mathrm{~cm})$. The motors moving the claws were buried underground so that only the claw was visible to the female. The area surrounding the choice 
arena was flat and treeless. The horizon behind the robotic males, when viewed from crab eye level, was uniform.

Mate-searching females were captured on the mudflat and placed in a container with water to prevent dehydration. A female was then placed under a clear plastic container at the release site. The robotic crabs were activated and the female left in the container for at least three wave cycles. The container was then lifted by the researcher with a remotely triggered lever $2 \mathrm{~m}$ from the female release point. We scored a positive choice if a female moved in a direct line to within $3 \mathrm{~cm}$ of a waving claw. Each female was used in one trial per experiment, but was reused in one to five other two-choice experiments. For all two-choice experiments potential side bias was eliminated by alternating the presentation of test stimuli between sides across trials. There was, however, no detectable side bias in any of the experiments (see Results).

In each experiment the robots were identical so there should be no significant difference in the number of females approaching each, unless the manipulations to the local environment affected male attractiveness. We ran the following experiments.

(1) Control: to test for a side bias, females could choose between two robots with no manipulation of the local environment on either side.

(2) Light level: one robot was in full sunlight, the other in shade. Shade was cast by suspending a piece of cardboard $(9 \times 17 \mathrm{~cm})$ from a dowel rod $1.5 \mathrm{~m}$ above the ground.

(3) Background complexity.

(a) A piece of cardboard $(15 \times 25 \mathrm{~cm})$ was placed directly behind each robot. The simple background was plain brown (sandy taupe) cardboard. The complex background was multicoloured cardboard created using the randomization option in Paint Shop Pro version 7.02 (Jasc Software, Minneapolis, U.S.A.). A random number generator yielded values between 0 and 255 representing hue, saturation and brightness to create a grid of 375 different $1 \mathrm{~cm}^{2}$ squares (Fig. 1).

(b) A piece of cardboard $(15 \times 21 \mathrm{~cm})$ was placed directly behind each robot. The simple background was a photograph of mud. The complex background was a photograph of a visually complex, natural setting: roots, mud lobster mounds, trees and leaves.

(c) To represent areas with abundant mangrove roots, six pieces of bamboo (50 $\mathrm{mm}$ high, $8 \mathrm{~mm}$ diameter) resembling mangrove roots were glued to a plywood base $(10 \times 6 \mathrm{~cm})$ then covered in mud. This was placed directly behind one robot. Another piece of muddy plywood was placed behind the other robot.

(d) To create a lobster excavation mound a pile of mud $9 \mathrm{~cm}$ high, $12 \mathrm{~cm}$ wide (at the base) was placed $4 \mathrm{~cm}$ behind one robot. Nothing was placed behind the other robot.

(e) Three yellow mangrove leaves (collected at the study site) were placed behind one robot. Nothing was placed behind the other robot.

(4) Foreground complexity: three pieces of bamboo (50 $\mathrm{mm}$ high, $8 \mathrm{~mm}$ diameter) resembling mangrove roots were glued to a plywood base $(10 \times 6 \mathrm{~cm})$ then covered in mud. This was placed directly in front of one robot. A second piece of mud-covered plywood was placed in front of the other robot.

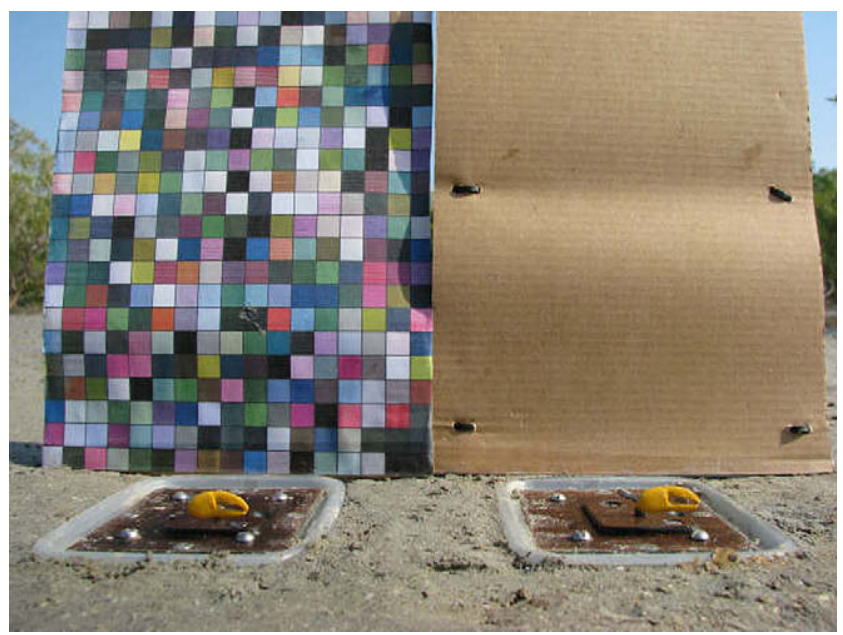

Figure 1. Photograph of robotic crabs in background complexity experiment $3 a$.

(5) The stimuli from experiments 2, 3c and 4 were run in combination to determine whether the combination of shade and increased background and foreground complexity decreased a male's attractiveness.

(6) Social complexity: local male density was manipulated by tethering two live male conspecifics (claw size: $15 \mathrm{~mm}$ ) 5 and $10 \mathrm{~cm}$ to the outside of one robot.

Finally, to distinguish between female choice for males versus habitats we conducted additional choice experiments in the field. A circular arena was drawn onto the mud that comprised two concentric circles (radii 50 and $40 \mathrm{~cm}$ ) and was divided into eight sectors (Fig. 2). The area between the two circles was termed the 'choice area'. In each of four sectors representing 'complex' habitat we

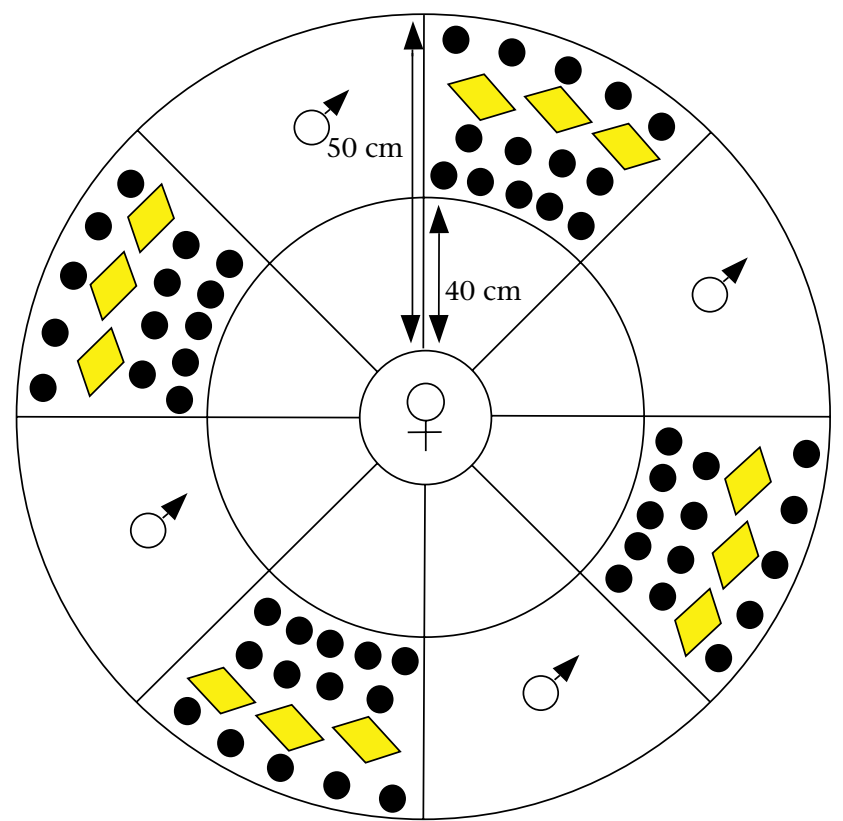

Figure 2. Diagram of the circular choice arena used in the habitat tests. $\varangle$ : Tethered male (applicable only for the second experiment); : female release point; $\boldsymbol{O}$ : bamboo; $\downarrow$ : yellow leaf. 
placed 14 pieces of bamboo that resembled mangrove roots and three mangrove leaves in the 'choice area'. We added nothing to the four 'simple habitat' sectors. Alternate sectors were complex and simple habitat. We placed a recently caught female under a plastic container in the arena centre and allowed her to settle. The container was then lifted using a remotely trigged lever and her sector/ habitat chosen noted. A positive choice was scored when she first entered a 'choice area'. In a follow-up experiment, we tethered a male in each of the four 'simple habitat' choice areas (Fig. 2) by gluing a $2 \mathrm{~cm}$ length of cotton to his carapace and affixing it to a nail embedded in the sediment. Females could therefore choose between complex habitat without a male and simple habitat with a male.

Unless otherwise stated, female preferences were tested with binomial tests (two tailed) with $\alpha=0.05$. To be conservative, two-tailed tests were used because we had no strong prior predictions for female preferences. The number of responses to each treatment is given for each experiment.

\section{RESULTS}

\section{Habitat Survey}

The environment surrounding males varied greatly, ranging from highly complex to comparatively simple habitats. Nearly half of the males surveyed occupied areas with abundant mangrove roots (46\%) and nearly $40 \%$ were in shade. In total, $38 \%$ of males were in areas with no mangrove roots, full sunlight and no shells or leaves (equivalent to controls in all 10 mate choice experiments). In contrast, $9 \%$ of males were in shaded areas with no mangrove roots, mud lobster mounds, shells or leaves (as in experiment 2); $13 \%$ were in areas with mangrove roots, full sunlight and no mud lobster mounds, shells or leaves (as in experiments 3c and 4); 6\% of males were in areas with abundant mangrove roots, shade and leaves (as in experiment $3 b) ; 13 \%$ of males surveyed were in shaded areas with abundant mangrove roots and no shells or leaves (as in experiment 5).

\section{Mate Choice Experiments}

The first experiment showed that there was no side bias in the choice arena (left versus right: 50:50; $N=30$, $P=1.0$ ). When all the two-choice experiments were pooled, the ratio of left to right responses was $235: 245$ $(P=0.68)$.

For each of the six two-choice experiments we ran 50 trials. Females showed no preference for waving claws that were in full sunlight rather than shade (experiment 2: shade versus light: $25: 25 ; P=1.0$ ). An increase in background complexity did not affect female mate choice in any of the five experiments in which it was manipulated (experiment 3: multicoloured versus plain brown background: $31: 19 ; P=0.12$; photograph of a complex, natural setting versus one of mud: $24: 26, P=0.89$; mangrove roots present versus absent: $31: 19 ; P=0.12$; mud mounds present versus absent: $28: 22 ; P=0.48$; leaves present versus absent: $22: 28$; $P=0.48)$. Increased foreground complexity also had no effect on female choice (experiment 4: mangrove roots present versus absent: $24: 26, P=0.89$ ). Even the combination of increased foreground and background complexity and shade had no effect on female choice (experiment 5: complex versus simple: $22: 28, P=0.48)$. Finally, the presence of other males (nonwaving) did not affect female choice (experiment 6: additional males present versus absent: $21: 29, P=0.32)$.

\section{Arena Experiments}

In the circular choice arena when no males were present, females preferentially approached sectors that contained complex habitat over simple habitat (23:7, $P=0.005)$. In contrast, when a male was present in the simple habitat sectors, females showed a significant preference for these sectors $(22: 8, P=0.016$; both experiments: $N=30$ trials).

\section{DISCUSSION}

Male $U$. mjoebergi occupy a wide range of habitats. They can signal from highly complex environments with dappled shade, among moving and structurally complex vegetation, on uneven mud surfaces and surrounded by conspecifics and heterospecifics. Alternatively, they can signal from relatively simple environments of flat, unvegetated areas in full sun and with no other crabs in the vicinity. The range of signalling environments is impressive.

There was no significant effect of the manipulation of light level, foreground or background complexity or the number of nearby males on female choice decisions in $U$. mjoebergi. This suggests that the conspicuousness, and by extension relative attractiveness, of male courtship signals was not affected by these environmental manipulations. If there was any effect, it was too small to detect, even though our sample sizes were larger than the average for most published two-choice mating trials (e.g. Wollerman \& Wiley 2002). The power to detect a medium strength effect (sensu Cohen 1988) with a sample size of 50 is $62 \%$. Our results suggest that sexual selection has led to the evolution of male signals that remain conspicuous and easily distinguished from the background across the full range of natural habitats in which they are transmitted (Uy \& Endler 2004). Our manipulations of environmental noise were insufficient to reduce signal detectability significantly (Witte et al. 2005). Clearly, the signalling system has evolved so that the female sensory system can compensate for environmental problems encountered along transmission paths and males can produce signals that stand out against the general environment in which they are produced. Given this, we might expect males to signal preferentially in habitats where it is less costly to do so. For example, if the physiological costs of waving are lower in the shade, since this has no effect on signal detectability, males should preferentially signal from shady areas.

Brightness contrast has long been recognized as a key feature that increases visual signals' conspicuousness (Endler 1990). The importance of lighting conditions has 
been shown in many taxa (e.g. lizards: Leal \& Fleishman 2002; birds: Endler \& Thery 1996; Gomez \& Thery 2004; fish: Fuller 2002). For example, in a manakin (Pipra erythrocephala) males primarily display in the shade; however, to attract females from a distance they display in sunny patches to increase the brightness contrast between their plumage and the background (Heindl \& Winkler 2003b). Although numerous studies emphasize the importance of lighting condition for visual signals, we showed that a waving fiddler crab claw is equally attractive whether it is in the shade or full sunlight. Our results corroborate recent work indicating that female $U$. mjoebergi do not discriminate between claws that differ in their inherent brightness but instead pay attention to colour differences (Detto 2007). If our findings apply to other fiddler crabs, they weaken the suggestion that $U$. elegans males avoid shady areas because of a reduction in signal conspicuousness (Nobbs 2003). Although brightness must ultimately affect ease of detection of a claw, the available evidence suggests that the difference in light level between shaded and exposed areas of the mudflat is insufficient to alter male attractiveness.

Contrary to many other studies of signal detectability, we found that male signals were equally attractive across a wide range of different signalling habitats. A partial explanation for these results comes from data on the spectral sensitivity of four other species of fiddler crab $(U$. pugnax, U. pugilator, U. tangeri and U. vomeris; Jordão et al. 2007). Owing to the presence of screening pigments lining the photoreceptor cells, the peak sensitivity is in the orange-red region of the spectrum. A visual system maximally sensitive to longer wavelengths enhances the contrast between yellow (longer wavelength) claws and vegetated backgrounds, which are primarily green or brown and thus emit shorter wavelengths. The screening pigments found in $U c a$ spp. are a general adaptation to bright environments (Cronin \& Forward 1988) and the resulting spectral sensitivity is common in the genus Uca (Jordão et al. 2007). It is therefore likely that U. mjoebergi share this spectral sensitivity. If so, all the signalling backgrounds used in our study are likely to remain in high contrast with the yellow claws of males. If female choice is primarily driven by colour contrast, this could explain the lack of an effect of background habitat on signal attractiveness. It does not, however, explain why increased foreground noise in the form of mangrove roots that partially obscured claws had no effect on female choice. The occlusion effect should reduce the total area of yellow claw visible to females and claw size is known to affect female choice (E. Curran, M. D. Jennions \& P. R. Y. Backwell, unpublished data). It is possible, however, that females can still estimate claw size by integrating information during their approach to build up a visual image of total claw size (e.g. maximum distance between areas of yellow).

One alternative explanation for our results is that the lack of an effect of signalling environment on male attractiveness is due to an additional female preference for specific habitats. That is, females might prefer a male signal in the simple signalling environment where it is more conspicuous, but simultaneously prefer complex over simple habitat because it provides greater cover during predation. It is well known that fiddler crabs are attracted to vertical structures when startled by predators (Christy 1988). In a field cricket (Gryllus integer) females preferentially approached males with longer call bouts when all else was equal. However, when offered a choice between a male with a long call bout and a male with a short call bout that could be approached under cover, females approached both males equally often (Hedrick \& Dill 1993). This suggests that female $G$. integer trade off approaching the preferred male trait and the predation risk associated with so doing (for another example see Backwell \& Passmore 1990). The same processes might have occurred in our mate choice experiments with $U$. mjoebergi, but our subsequent habitat choice experiments weaken this explanation. Although females did have a clear preference for a complex over a simple habitat when males were absent, this preference disappeared when females were placed into a mate-searching context (i.e. when males were present in the simple habitat).

Manipulation of social complexity, in the form of increasing local male density, had no influence on female choice in $U$. mjoebergi. In contrast, observations in the wild of another fiddler crab, U. vocans, show that females actively avoid large groups of males, possibly to avoid the risk of harassment (Salmon 1984). Although the males in this experiment were tethered and therefore unable to harass the females, the female's perception of a risk of harassment would presumably be unaltered. In general, the effect of increased male density on female choice is inconsistent across taxa. In some cases, too much choice can confuse females and reduce the rate at which they approach male groups (reviewed in Hutchinson 2005). In other cases, a female preference for an increased number of options to choose from might explain male clustering and lek formation (Höglund \& Alatalo 1995). At present, our results provide limited evidence as to how male density will influence female choice in the field. This is because tethered males did not produce courtship waves. In future studies, as we build more robotic crabs, we will be able to test experimentally the independent effects on female mate choice of male density and the total number of signals from an area per unit time.

\section{Acknowledgments}

We thank Isobel Booksmythe, Tanya Detto, Jess Bolton and Melita Baum for assistance. We also thank two anonymous referees for providing helpful comments. Research was funded by the Australian Research Council (to P.R.Y.B. and M.D.J.) and an Australian Geographic Society grant (to R.M.).

\section{References}

Andersson, M. 1994. Sexual Selection. Princeton, New Jersey: Princeton University Press.

Andersson, S., Rydell, J. \& Svensson, M. G. E. 1998. Light, predation and the lekking behaviour of the ghost swift Hepialus humuli (L.) (Lepidoptera: Hepialidae). Proceedings of the Royal Society of London, Series B, 265, 1345-1351. 
Backwell, P. R. Y. \& Passmore, N. I. 1990. Suitable approach perches affect female phonotaxis in an arboreal frog. Herpetologica, 46, 11-14.

Bradbury, J. W. \& Vehrencamp, S. L. 1998. Principles of Animal Communication. Sunderland, Massachusetts: Sinauer Associates.

Christy, J. H. 1980. The mating system of the sand fiddler crab. Ph.D. thesis, Cornell University.

Christy, J. H. 1988. Pillar function in the fiddler crab Uca beebei (II): competitive courtship signalling. Ethology, 78, 113-128.

Chunco, A. J., McKinnon, J. S. \& Servedio, M. R. 2007. Microhabitat variation and sexual selection can maintain male color polymorphisms. Evolution, 61, 2504-2515.

Cohen, J. 1988. Statistical Power Analysis for the Behavioral Sciences. 2nd edn. Hillsdale, New Jersey: L. Erlbaum.

Crane, J. 1975. Fiddler Crabs of the World (Ocypodidae: Genus Uca). Princeton, New Jersey: Princeton University Press.

Cronin, T. W. \& Forward, R. B. 1988. The visual pigments of Crabs. 1: spectral characteristics. Journal of Comparative Physiology A, Sensory Neural and Behavioral Physiology, 162, 463-478.

Detto, T. 2007. The fiddler crab Uca mjoebergi uses colour vision in mate choice. Proceedings of the Royal Society of London, Series B, 274, 2785-2790.

Doucet, S. M., Mennill, D. J. \& Hill, G. E. 2007. The evolution of signal design in manakin plumage ornaments. American Naturalist, 169, S62-S80.

Endler, J. A. 1990. On the measurement and classification of color in studies of animal color patterns. Biological Journal of the Linnean Society, 41, 315-352.

Endler, J. A. 1991. Variation in the appearance of guppy color patterns to guppies and their predators under different visual conditions. Vision Research, 31, 587-608.

Endler, J. A. 1992. Signals, signal conditions, and the direction of evolution. American Naturalist, 139, S125-S153.

Endler, J. A. \& Thery, M. 1996. Interacting effects of lek placement, display behavior, ambient light, and color patterns in three neotropical forest-dwelling birds. American Naturalist, 148, 421-452.

Fuller, R. C. 2002. Lighting environment predicts the relative abundance of male colour morphs in bluefin killifish (Lucania goodei) populations. Proceedings of the Royal Society of London, Series B, 269, 1457-1465.

Gomez, D. \& Thery, M. 2004. Influence of ambient light on the evolution of colour signals: comparative analysis of a Neotropical rainforest bird community. Ecology Letters, 7, 279-284.

Guilford, T. \& Dawkins, M. S. 1993. Receiver psychology and the design of animal signals. Trends in Neurosciences, 16, 430-436.

Hedrick, A. V. \& Dill, L. M. 1993. Mate choice by female crickets is influenced by predation risk. Animal Behaviour, 46, 193-196.

Heindl, M. \& Winkler, H. 2003a. Interacting effects of ambient light and plumage color patterns in displaying wire-tailed manakins (Aves, Pipridae). Behavioral Ecology and Sociobiology, 53, 153-162.

Heindl, M. \& Winkler, H. 2003b. Vertical lek placement of forestdwelling manakin species (Aves, Pipridae) is associated with vertical gradients of ambient light. Biological Journal of the Linnean Society, 80, 647-658.

Höglund, J. \& Alatalo, R. 1995. Leks. Princeton, New Jersey: Princeton University Press.

Hutchinson, J. M. C. 2005. Is more choice always desirable? Evidence and arguments from leks, food selection, and environmental enrichment. Biological Reviews, 80, 73-92.

Jordão, J. M., Cronin, T. W. \& Oliveira, R. F. 2007. Spectral sensitivity of four species of fiddler crabs (Uca pugnax, Uca pugilator, Uca vomeris and Uca tangeri) measured by in situ microspectrophotometry. Journal of Experimental Biology, 210, 447-453.
Leal, M. \& Fleishman, L. J. 2002. Evidence for habitat partitioning based on adaptation to environmental light in a pair of sympatric lizard species. Proceedings of the Royal Society of London, Series $B$, 269, 351-359.

Lindquist, E. D. \& Hetherington, T. E. 1996. Field studies on visual and acoustic signalling in the 'earless' Panamanian golden frog, Atelopus zeteki. Journal of Herpetology, 30, 347-354.

Morrell, L. J., Backwell, P. R. Y. \& Metcalfe, N. B. 2005. Fighting in fiddler crabs Uca mjoebergi: what determines duration? Animal Behaviour, 70, 653-662.

Morton, E. S. 1975. Ecological sources of selection on avian sounds. American Naturalist, 109, 17-34.

Nobbs, M. 2003. Effects of vegetation differ among three species of fiddler crabs (Uca spp.). Journal of Experimental Marine Biology and Ecology, 284, 41-50.

Ord, T. J., Peters, R. A., Clucas, B. \& Stamps, J. A. 2007. Lizards speed up visual displays in noisy motion habitats. Proceedings of the Royal Society of London, Series B, 274, 1057-1062.

Patricelli, G. L. \& Blickley, J. L. 2006. Avian communication in urban noise: causes and consequences of vocal adjustment. Auk, 123, 639-649.

Reading, K. L. \& Backwell, P. R. Y. 2007. Can beggars be choosers? Male mate choice in a fiddler crab. Animal Behaviour, 74, 867-872.

Reaney, L. T. \& Backwell, P. R. Y. 2007a. Risk-taking behavior predicts aggression and mating success in a fiddler crab. Behavioral Ecology, 18, 521-525.

Reaney, L. T. \& Backwell, P. R. Y. 2007b. Temporal constraints and female preference for burrow width in the fiddler crab, Uca mjoebergi. Behavioral Ecology and Sociobiology, 61, 1515-1521.

Reaney, L. T., Sims, R. A., Sims, S. W. M., Jennions, M. D. \& Backwell, P. R. Y. 2008. Experiments with robots explain synchronized courtship in fiddler crabs. Current Biology, 18, 62-63.

Ryan, M. J. 2007. Sensory ecology: see me, hear me. Current Biology, 17, R1019-R1021.

Salmon, M. 1984. The courtship, aggression and mating system of a 'primitive' fiddler crab (Uca vocans: Ocypodidae). Transactions of the Zoological Society of London, 37, 1-50.

Slabbekoorn, H. \& Peet, M. 2003. Ecology: birds sing at a higher pitch in urban noise. Great tits hit the high notes to ensure that their mating calls are heard above the city's din. Nature, 424, 267.

Stuart-Fox, D., Moussalli, A. \& Whiting, M. J. 2007. Natural selection on social signals: signal efficacy and the evolution of chameleon display coloration. American Naturalist, 170, 916-930.

Swaddle, J. P. \& Page, L. C. 2007. High levels of environmental noise erode pair preferences in zebra finches: implications for noise pollution. Animal Behaviour, 74, 363-368.

Uy, J. A. C. \& Endler, J. A. 2004. Modification of the visual background increases the conspicuousness of golden-collared manakin displays. Behavioral Ecology, 15, 1003-1010.

Warren, P. S., Katti, M., Ermann, M. \& Brazel, A. 2006. Urban bioacoustics: it's not just noise. Animal Behaviour, 71, 491-502.

Wiley, R. H. 2006. Signal detection and animal communication. Advances in the Study of Behavior, 36, 217-247.

Witte, K., Farris, H. E., Ryan, M. J. \& Wilczynski, W. 2005. How cricket frog females deal with a noisy world: habitat-related differences in auditory tuning. Behavioral Ecology, 16, 571-579.

Wollerman, L. 1999. Acoustic interference limits call detection in a Neotropical frog Hyla ebraccata. Animal Behaviour, 57, 529-536.

Wollerman, L. \& Wiley, R. H. 2002. Background noise from a natural chorus alters female discrimination of male calls in a Neotropical frog. Animal Behaviour, 63, 15-22. 